\title{
General practitioner burnout in Singapore and the role of Balint groups
}

\author{
Eugene Kin Mun Wuan ${ }^{1}$, MBBS, MRCPsych, Yew Seng ${\underline{T^{2}}}^{2}$, FCFPS, FAMS, Siew Peng Soon ${ }^{1}$, PhD, MPsych,
} Andre Teck Sng Tay ${ }^{1}$, MBBS, MRCPsych

\section{INTRODUCTION}

The scope of general practitioner (GP) services in Singapore is diverse, ranging from the traditional GP in a solo family practice to physicians in group practice and polyclinics; generalists in acute hospitals, community hospitals and hospices; and physicians in occupational facilities and locum practices. About $80 \%$ of the demand for primary care is met by the 1,700 private GP clinics in Singapore. (1) In such a heterogeneous group, the work stressors faced by GPs are bound to vary. Unfortunately, the phenomenon of burnout among GPs in Singapore has not yet been studied, although burnout is known to occur among other physicians in Singapore and GPs elsewhere. ${ }^{(2-6)}$

\section{BURNOUT AMONG GENERAL PRACTITIONERS IN SINGAPORE}

General practice has a unique value and benefits that attract and sustain its practitioners. An example might be the level of autonomy, especially among GPs in private practice. Another advantage might be the flexible hours and absence of after-hours on-call duties. However, at the same time, the nature of the work and the work environment of GPs in Singapore point to certain factors that may lead to job burnout. ${ }^{(7)}$

For one, it is well known that many private GP clinics customarily operate seven days a week, while patient caseloads in the polyclinics are also high. ${ }^{(8)}$ Exhaustion, a defining feature of burnout, can result simply from chronic exposure to high workload or lack of rest.

In a typical practice, GPs are routinely called upon to attend to undifferentiated clinical situations, ${ }^{(9)}$ some of which may be layered with psychological and social issues. In community management of patients with chronic illnesses, the GP inevitably has to address the challenges of the patient living with the disease and its treatment. This differs significantly from hospital-based practice, where the focus of management primarily pertains to disease pathology. The intensity of this work, which may involve social and psychological issues, is known to take its toll on GPs. ${ }^{(10)}$ While the biopsychosocial approach has long been touted as the defining approach for general practice, ${ }^{(11)}$ the conventional medical curriculum is often weighted more heavily towards clinical science, and aspects that confer interpersonal skills are usually given an intellectualised or impersonalised gloss by academics and experts from hospital-based practices.
Certain systemic issues in general practice may also engender burnout. For example, GPs tend to work alone and independently, without any clinical team or formal structure for support, or clinical governance apart from professional ethics and regulations. This is particularly true for private GP practices, which also have to contend with the challenges of clinical and financial viability without external resources. GPs can only rely on themselves to foster connections with others and obtain support from the relevant educational or regulatory bodies and societies.

A recent emphasis on the importance of upstream preventive care in disease management comes with increased expectations on GPs to provide new treatments and management protocols. Updated reporting and auditing processes in the modern Internet era require older practices to reinvent themselves to stay relevant or in compliance. The expectations of patients and families have also increased as they become aware of the various treatment options and alternatives, and they are less likely to accept the $\mathrm{GP}^{\prime} \mathrm{s}$ recommendations without question.

Hence, a significant proportion of GPs are likely overworked; isolated; emotionally over-aroused by patients with intense psychosocial issues; overwhelmed by expectations from patients, families and health authorities; feeling illequipped to grapple with the clinical and financial realities of practice; and perhaps lacking adequate social support themselves. It is conceivable that exhausted GPs may be emotionally detached from patients, regarding them as objects, symptoms or diseases as a coping mechanism to protect themselves from intense emotional arousal that may interfere with clinical tasks. Unfortunately, their resulting detached, callous, cynical or dehumanised demeanour is unlikely to help and may even worsen any sense of their incompetence. This is a concern, because the capacity to stay engaged and empathetic is necessary for appropriate and effective care, and also to prevent or alleviate burnout.

\section{ORGANISATION-AND INDIVIDUAL- FOCUSED INTERVENTIONS TARGETING PHYSICIAN BURNOUT}

As burnout is an established concern among physicians, interventions to treat burnout and promote wellness are critical. These interventions can be categorised into two domains: organisation focused and individual focused. ${ }^{(12,13)}$ Both categories

${ }^{1}$ Department of Psychological Medicine, Changi General Hospital, ${ }^{2}$ OncoCare Cancer Centre, Gleneagles Medical Centre, Singapore

Correspondence: Dr Eugene Wuan Kin Mun, Consultant, Department of Psychological Medicine, Changi General Hospital, 2 Simei Street 3 , Singapore 529889. eugene.wuan.k.m@singhealth.com.sg 
of interventions were shown to be important in reducing physician burnout. ${ }^{(13,14)}$

Organisation-focused interventions, which have largely been studied in hospital settings, include improvement of hospital governance and management systems, workflow, communication and clinical processes, and management of physicians' ${ }^{\prime}$ orkloads. ${ }^{(13,15)}$

Individual-focused interventions are employable by physicians themselves and include both personal and professional strategies. Personal strategies relate to general self-care, such as eating nutritious food, spending time with family, getting enough sleep, exercising regularly and addressing one's own medical issues. ${ }^{(3,16)}$ Beyond basic self-care, professional strategies include engaging in continuing medical education, seeking peer support (both informal and formal), developing skills to enhance selfawareness (e.g. connecting with the meaning and purpose found in work, cognitive behavioural techniques, communication skills, applying mindfulness) and learning how to practise self-care. ${ }^{(13-18)}$

In the current culture of medicine, physicians are rewarded for self-reliance, independent judgement and self-sacrifice, which unfortunately encourages neglect of self-care and personal wellness. ${ }^{(12)}$ Similarly, failing to live up to the impossible standards of being resilient and infallible is stigmatised. ${ }^{(15)}$ This is made worse as the medical profession is characterised by a lack of mutual support and feedback. ${ }^{(12)}$ Consequently, physicians commonly use ineffective coping strategies, including denial and avoidance. ${ }^{(19)}$

Nonetheless, as outlined above, peer support is a critical aspect of individual-focused professional interventions. It has been proposed that beyond formal or informal peer support arrangements, continuing medical education sessions may function not only as an avenue for disseminating and sharing information but also as a source of support for members in the learning group. ${ }^{(16)}$ Studies on physicians, medical students and residents have found that those who are adequately supported by their colleagues are able to achieve a sense of equilibrium, ${ }^{(20)}$ feel more validated and less stressed, ${ }^{(21)}$ and demonstrate improvement in burnout. ${ }^{(22)}$ Building a community and connectedness at work is paramount to helping physicians navigate professional challenges ${ }^{(23)}$ and reducing burnout. ${ }^{(3,22)}$

\section{GENERAL PRACTITIONERS UNIQUELY SUITED FOR BALINT GROUPS}

GPs are in the unique position of working alone and independently even as they encounter emotionally charged situations; have difficult interactions with demanding patients; and often witness suffering, anxiety and death. ${ }^{(24)}$ Sharing these experiences with peers may allow them to overcome and unburden themselves of these challenging experiences. ${ }^{(24)}$ However, their practice settings may make it more challenging to seek peer support from colleagues, creating a sense of isolation, which often leads to them feeling overwhelmed, conflicted and helpless, consequently placing them at a higher risk of burnout. ${ }^{(24)}$

As such, continuing medical education and peer support are crucial individual-focused professional interventions for reducing burnout among GPs, both of which are found in Balint groups. In general, Balint groups are small, consistent groups typically consisting of nine or ten individuals, led by a practitioner who preferably has psychodynamic training. Sessions last for an hour and are usually conducted at least once a month. These groups aim to provide a space whereby members feel safe to share and better understand the dynamics of the physician-patient relationship. Members are encouraged to reflect on emotional experiences that have been triggered by interactions with their patients. Issues of transference and countertransference are highlighted and discussed. This process of peer support, as well as shared exploration and reflection, helps members to feel less isolated and, consequently, less burnt out. ${ }^{(24)}$

With a specific focus on physician-patient relationships, Balint groups aim to normalise struggles and emotions that arise in patient interactions and support physicians in developing strategies to handle difficult interactions, thereby creating a collegial avenue for peer support. This may be especially valuable in GP settings, where physicians tend to practise alone. They also provide a safe space for GPs to receive support and feedback, which eases their psychological burden, validates their emotions and aids them in developing strategies to manage difficult situations. ${ }^{(24)}$

\section{BENEFITS OF BALINT GROUPS}

By reducing burnout, Balint groups can help GPs to adopt an objective observing stance and thus better understand the dynamic interactions between them and their patients. Processing the emotional content of the encounter allows them to better manage their patients in an objective manner that is purely in the patients' best interests and unclouded by the emotional reactions of either party. ${ }^{(25)}$

With the help of Balint groups, GPs are better able to recall and understand why they entered the profession of helping, and are also made aware of their own internal resources to adapt and cope. ${ }^{(26)}$ Balint groups can help GPs to discover the extensive value of their interpersonal skills and understand their own limitations. These skills enable them to better grasp the meaning of what their patients communicate. In addition, the process of self-discovery helps them to understand their blind spots when they interact with certain patients. ${ }^{(27)}$

Through the concept of universality regarding issues experienced by its members, Balint groups help GPs to understand and realise that they are not alone in having to deal with challenging patients. They provide opportunities for GPs to discuss thorny or complex treatment relationships with colleagues and to normalise their own emotional reactions. With mutual sharing, they are able to better appreciate and reformulate the boundaries between themselves and their patients, and rediscover the meaning in their work. They can then better understand and empathise with patients and become more adept at handling difficult interactions, leading to a reduced sense of isolation, higher job satisfaction, lower burnout risk and improved physician-patient relationships.

Studies show that participation in Balint groups increased the competence of the members in gaining control of encounters 
with their patients and managing difficult emotions in themselves and the patients. Members of Balint groups were better able to acknowledge and discuss emotions and identify the roots of these emotions, which can arise from their personal issues as well as from their patients. They developed more self-awareness, which helped them to better prepare for difficult encounters, and were better able to understand the mechanisms of these bad encounters and hence appreciate the patient as a whole person with unique difficulties. This allowed them to understand why patients behaved the way they did and to be more proactive in consultations. $^{(24)}$

GPs can incorporate the lessons learnt from Balint groups into practice, such that with time, they can intuitively apply these skills when they encounter challenging patients. ${ }^{(28)}$ Balint groups encourage safe discussion that is free of judgement, while carefully balancing the perspective of the GP against that of the patient. Encouraging introspection and the development of healthy relationships among members could bring about powerful experiences that are imperative for the personal growth of the members. This growth results in enhanced interpersonal relationships, a feeling of being rejuvenated, healthier living, increased productivity at work ${ }^{(29)}$ and increased job satisfaction. ${ }^{(30)}$

GPs are often expected to make treatment decisions automatically and intuitively, which requires adequate information from the patient and a balanced emotional state. ${ }^{(31)}$ They are expected to perform rapid pattern recognition in a timesensitive and stressful environment, amid the distraction of the emotional 'noise' in the interaction, and to provide appropriate treatment to the patient's satisfaction. To achieve this, the GP has to learn when to rely on intuition and when to practise reasoning via reflection-in-action. Balint groups help GPs become more proficient at this by providing a safe space where they can discuss issues pertaining to the physician-patient relationship with colleagues who share their struggles and who can better empathise with them. ${ }^{(32)}$

\section{BALINT GROUPS IN THE LOCAL CONTEXT}

As Balint groups mainly address the psycho-emotional aspect of the physician-patient relationship, it should not be the only measure employed in alleviating burnout. Other aspects of burnout, such as heavy workload and long hours, are better addressed by measures such as self-care or organisational interventions.

Balint groups are still relatively new in our local context. Currently, there is no regulatory body, such as a Balint Society that exists in other countries, that standardises or facilitates the formal running of Balint groups. Thus, challenges that one might face in running Balint groups include obtaining accreditation for Balint group leaders, obtaining buy-in from GPs and finding an equilibrium in session frequency, such that they neither impinge on the busy schedule of GPs nor are too infrequent and lose momentum in fostering a safe space for members. In the Asian context, members may need some time to warm up to one another before feeling safe enough to share spontaneously, which is another consideration when deciding on session frequency. With the recent
COVID-19 pandemic, safe distancing measures also have to be considered, and Balint groups may have to be held virtually.

Although it is beyond the scope of this article, it should be noted that there is a paucity of local research on burnout in GPs and on Balint groups. Future quantitative or qualitative research studies could focus on these areas.

It must also be noted that Balint groups are different from support groups or focus groups. Balint groups emphasise the physician-patient relationship, highlight issues of transference and counter-transference, and help members process the emotions that arise as a result of this. They also differ from communication courses, as they are spontaneous in nature, and do not have a set curriculum that covers specific skills.

\section{CONCLUSION}

GPs play a key role in our healthcare system. However, the nature of the work can predispose them to developing burnout, which in turn impacts the physician-patient relationship and patient care. Thus, self-care is essential to mitigate the effects of, or even prevent, burnout among GPs. The Balint group is a useful avenue for alleviating burnout, among its other benefits. Its use in the community of GPs warrants further exploration and implementation.

\section{REFERENCES}

1. Ministry of Health, Singapore. Primary healthcare services. Available at: https://www.moh.gov.sg/home/our-healthcare-system/healthcare-services-andfacilities/primary-healthcare-services. Accessed August 5, 2020.

2. Zenasni $F$, Boujut E, Woerner A, Sultan S. Burnout and empathy in primary care: three hypotheses. Br J Gen Pract 2012; 62:346-7.

3. Shanafelt TD, Dyrbye LN, West CP. Addressing physician burnout: the way forward. JAMA 2017; 317:901-2

4. Van Ham I, Verhoeven AAH, Groenier KH, Groothoff JW, De Haan J. Job satisfaction among general practitioners: a systematic literature review. Eur J Gen Pract 2006; 12:174-80.

5. See KC, Lim TK, Kua EH, et al. Stress and burnout among physicians: prevalence and risk factors in a Singaporean internal medicine programme. Ann Acad Med Singap 2016; 45:471-4.

6. Lee PT, Loh J, Sng G, Tung J, Yeo KK. Empathy and burnout: a study on residents from a Singapore institution. Singapore Med J 2018; 59:50-4.

7. Maslach C, Schaufeli WB, Leiter MP. Job burnout. Annu Rev Psychol 2001; 52:397-422.

8. Khalik S, Lee N. A longer wait now to see polyclinic doctor. The Straits Times 2017 Jun 27.

9. Alam R, Cheraghi-Sohi S, Panagioti M, et al. Managing diagnostic uncertainty in primary care: a systematic critical review. BMC Fam Pract 2017; 18:79.

10. Zantinge EM, Verhaak PFM, Bensing JM. The workload of GPs: patients with psychological and somatic problems compared. Fam Pract 2005; 22:293-7.

11. Mc Inerney SJ. Introducing the biopsychosocial model for good medicine and good doctors. Available at: https://www.bmj.com/rapid-response/2011/10/29/ introducing-biopsychosocial-model-good-medicine-and-good-doctors. Accessed August 5, 2020

12. Wallace JE, Lemaire JB, Ghali WA. Physician wellness: a missing quality indicator. Lancet 2009; 374:1714-21.

13. West CP, Dyrbye LN, Erwin PJ, Shanafelt TD. Interventions to prevent and reduce physician burnout: a systematic review and meta-analysis. Lancet 2016; 388:2272-81.

14. West CP, Dyrbye LN, Shanafelt TD. Physician burnout: contributors, consequences and solutions. J Intern Med 2018; 283:516-29.

15. Card AJ. Physician burnout: resilience training is only part of the solution. Ann Fam Med 2018; 16:267-70

16. Lee FJ, Stewart M, Brown JB. Stress, burnout, and strategies for reducing them: What's the situation among Canadian family physicians? Can Fam Physician 2008; 54:234-5.

17. Panagioti $\mathrm{M}$, Panagopoulou $\mathrm{E}$, Bower $\mathrm{P}$, et al. Controlled interventions to reduce burnout in physicians: a systematic review and meta-analysis. JAMA Intern Med 2017; 177:195-205

18. Romani M, Ashkar K. Burnout among physicians. Libyan J Med 2014; 9:23556. 
19. Baldisseri MR. Impaired healthcare professional. Crit Care Med 2007; 35(2 Suppl):S106-16.

20. Wallace JE, Lemaire J. On physician well being--you'll get by with a little help from your friends. Soc Sci Med 2007; 64:2565-77.

21. Ishak W, Nikravesh R, Lederer S, et al. Burnout in medical students: a systematic review. Clin Teach 2013; 10:242-5.

22. Busireddy KR, Miller JA, Ellison K, et al. Efficacy of interventions to reduce resident physician burnout: a systematic review. J Grad Med Educ 2017; 9:294-301

23. Shanafelt TD, Noseworthy JH. Executive leadership and physician well-being: nine organizational strategies to promote engagement and reduce burnout. Mayo Clin Proc 2017; 92:129-46.

24. Kjeldmand D, Holmström I. Balint groups as a means to increase job satisfaction and prevent burnout among general practitioners. Ann Fam Med 2008; 6:138-45.

25. Victorian Foundation for Survivors of Torture Inc, Australia. Rebuilding Shattered
Lives. Victoria: Victorian foundation for Survivors of Torture Inc, 1998.

26. Stebnicki M. Stress and grief reactions among rehabilitation professionals: dealing effectively with empathy fatigue. J Rehabil 2000; 66:23-9.

27. Samuel OW. Aims and objectives of Balint training. J Balint Soc 1987; 15:23-5.

28. Borrell-Carrió F, Epstein RM. Preventing errors in clinical practice: a call for self-awareness. Ann Fam Med 2004; 2:310-6.

29. Kern DE, Wright SM, Carrese JA, et al. Personal growth in medical faculty: a qualitative study. West J Med 2001; 175:92-8

30. Cataldo KP, Peeden K, Geesey ME, Dickerson L. Association between Balint training and physician empathy and work satisfaction. Fam Med 2005; 37:328-31.

31. Kahneman D. A perspective on judgment and choice: mapping bounded rationality. Am Psychol 2003; 58:697-720.

32. Lichtenstein A. Integrating intuition and reasoning--how Balint groups can help medical decision making. Aust Fam Physician 2006; 35:987-9. 